\title{
Effect of dietary elaidic versus vaccenic acid on blood and liver lipids in the hamster
}

\author{
G.W. Meijer ${ }^{\mathrm{a}, *}$, A. van Tol ${ }^{\mathrm{b}}$, Th.J.C. van Berkel ${ }^{\mathrm{c}}$, J.A. Weststrate ${ }^{\mathrm{a}}$ \\ ${ }^{a}$ Unilever Health Institute, Unilever Research, P.O. Box 114, 3130 AC Vlaardingen, The Netherlands \\ ${ }^{\mathrm{b}}$ Department of Biochemistry, Cardiovascular Research Institute (COEUR), Erasmus University, P.O. Box 1738, \\ 3000 DR Rotterdam, The Netherlands \\ ${ }^{\mathrm{c}}$ Division of Biopharmaceutics, Leiden/Amsterdam Center for Drug Research, Sylvius Laboratory, P.O. Box 9503, \\ 2300 RA Leiden, The Netherlands
}

Received 10 March 2000; received in revised form 7 August 2000; accepted 1 September 2000

\begin{abstract}
Male hamsters (30 per group) were fed five different semi-purified diets ad libitum. The diets, containing 30\% of energy (en\%) as fat, differed in their dietary fat composition (specified fatty acids exchanged at $10 \mathrm{en} \%$ ) and were fed for 4 weeks. The five fatty acids compared in mixed triglycerides were elaidic acid (C18:1 9t), vaccenic acid (C18:1 11t), their cis-counterpart oleic acid (C18:1 9c), medium-chain fatty acids (MCFA; C8:0 and C10:0), and palmitic acid (C16:0). Compared with oleic acid, dietary MCFA and palmitic acid tended to increase blood cholesterol levels in the hamsters. The effect of elaidic and vaccenic acid on blood cholesterol did not differ from that of oleic acid. When elaidic acid and vaccenic acids were compared directly, the ratio of LDL/HDL-cholesterol in plasma was significantly higher in hamsters fed vaccenic acid than in those fed elaidic acid, and elaidic acid was incorporated at low levels, but more efficiently than vaccenic acid at the $s n-2$ position of platelet phospholipids. Biological consequences of this low incorporation are considered unlikely as levels of arachidonic acid (C20:4 n- 6$)$ and docosohexaenoic acid (C22:6 n-3) in the platelet phospholipids of all dietary groups did not differ. With respect to the effect on the LDL/HDL-cholesterol ratio, elaidic acid may be preferable to vaccenic acid. We conclude that this animal study does not provide evidence for the suggestion, based on epidemiological observations, that elaidic acid would be more detrimental to cardiovascular risk than vaccenic acid. (c) 2001 Elsevier Science Ireland Ltd. All rights reserved.
\end{abstract}

Keywords: trans-fatty acids; Saturated fatty acids; Phospholipids; Lipoproteins; Triglycerides; CETP; LCAT

\section{Introduction}

Epidemiological studies in the United States of America have suggested that dietary trans-fatty acids from partially hydrogenated vegetable oils, as found in margarine, but not those from ruminant fats, present in butter, are associated with an increased risk of coronary heart disease in women [1,2]. Moreover, in the Scottish Heart Health Study dietary intake of total or partially hydrogenated vegetable oils-derived trans-fatty acids, but not of naturally occurring trans-fatty acids (mainly ruminant), tended to be positively associated

\footnotetext{
* Corresponding author. Present address: Lipton, 800 Sylvan Avenue, Englewood Cliffs, NJ, USA. Tel.: + 1-201-8947126; fax: + 1201-8718133.

E-mail address: gert.meijer@unilever.com (G.W. Meijer).
}

with risk of coronary heart disease in women [3]. The observed difference in effect of the two types of transfatty acids on risk of coronary heart disease is attributed to the distinct structure of the primary trans-isomer in ruminant fat, i.e. vaccenic acid, which has the double bond at the 11 as opposed to the 9 position in elaidic acid, the predominant but not exclusive trans-isomer in partially hydrogenated vegetable oils. However, there is no clear biological explanation for such a differential effect. In human skin fibroblasts, elaidic acid has been shown to be a more potent inhibitor of $\Delta 6$-desaturase in vitro than vaccenic acid [4], whereas the opposite was observed in rat liver microsomes [5]. These findings, however, can not directly be related to coronary heart disease.

No metabolic studies have been published in which elaidic acid is directly compared with vaccenic acid in 
dietary triglycerides. In the present study both transfatty acids were therefore compared in hamsters with their cis-counterpart oleic acid; medium-chain fatty acids, which have been reported to have neutral effects on blood lipids [6]; and palmitic acid, which is hypercholesterolemic in the hamster [6]. The average human trans-fatty acids intake (as mixture of isomers) is around $2 \%$ of energy (en $\%$ ) [7]. The intake of the two trans-fatty acids isomers in this experiment was set at the high level of $10 \mathrm{en} \%$ to enable detection of differential effects, if any. The hamster was used as an animal model because lipid metabolism in this rodent species resembles human lipid metabolism more than that in rats or mice [8,9]. Elaidic acid and vaccenic acid were each randomly incorporated in dietary triglycerides.

Theoretically, the two trans-fatty acids could have a differential impact on lipid and eicosanoid metabolism in vivo, which in turn could explain a differential effect on coronary heart disease risk, if any. In the current study those aspects of lipid and eicosanoid metabolism were investigated that either have been reported, or were considered most likely to be effected by trans-fatty acid intake. The parameters measured were plasma lipids and lipoproteins, lipid transfer and transferase protein activities. In man dietary trans-fatty acids have been reported to simultaneously increase LDL-cholesterol and decrease HDL-cholesterol, or at least to raise the ratio LDL/ HDL-cholesterol, when compared with oleic acid [10]. Lecithin:cholesterol acyltransferase (LCAT) and phospholipid transfer protein (PLTP) are HDL-bound enzymes. Previous studies have shown that cholesteryl ester transfer protein (CETP) activity, measured either with endogenous [11] or exogenous [12] substrates, may be affected by dietary trans-fatty acids in humans. To predict whether the two trans-fatty acids would have the potential to differentially affect eicosanoid metabolism [1], the fatty acid distribution in phospholipids was also determined.

\section{Materials and methods}

\subsection{Animals and design}

The experimental protocol was approved by the Animal Experiments Committee of the Unilever Research Laboratory, Vlaardingen, The Netherlands.

A total of 150 male $F_{1} B$ hybrid Syrian (golden) hamsters, aged 10-11 weeks at arrival, were obtained from Biobreeder Inc., Fitchburg, US. The study was designed to have a large statistical power to be able to detect small differences between dietary treatments.

The hamsters were housed individually in Makrolon cages type II, with a layer of sawdust as bedding, in a room with controlled lighting (light, 07:00-19:00 h), temperature $\left(22-24^{\circ} \mathrm{C}\right)$ and relative humidity $(45-65 \%)$. After an adaptation period of 3 weeks, plasma cholesterol concentration was determined and the hamsters were allocated to five groups of 30 animals each on the basis of similar means and distributions of plasma total cholesterol concentration and body weight. Five different diets were fed during four weeks. Body weight was measured weekly and food consumption was determined during four consecutive days in the second and the last week of the experiment. Non-fasted hamsters were anaesthetized with a mixture of $\mathrm{N}_{2} \mathrm{O} / \mathrm{O}_{2} /$ Halothane, killed by decapitation after blood sampling by orbital puncture, and autopsy was performed subsequently.

\subsection{Dietary fats and diets}

Elaidic acid (trans-9-octadecenoic acid; E-4637) and vaccenic acid (trans-11-octadecenoic acid; V-1131) were obtained from Sigma Chemicals (US). Five test fats (blends) were prepared, which differed in their fatty acid composition. A fat blend rich in mediumchain fatty acids (MCFA) was obtained by mixing $33.3 \%$ medium chain triglycerides-oil (Ceres MCT, Union Deutsche Lebensmittel Werke $\mathrm{GmbH}$, Kleve, Germany), $6.0 \%$ cacao butter, $13.7 \%$ dry-fractionated palm oil-stearin fraction, $2.4 \%$ linseed oil, $13.7 \%$ safflower oil, plus $30.9 \%$ high-oleic sunflower oil (Trisun-80, SVO, OH, US). A fat blend rich in palmitic acid (SAFA) was prepared by mixing 53.2\% wet-fractionated palm oil-stearin fraction, $2.3 \%$ linseed oil, $17.3 \%$ safflower oil, plus $27.2 \%$ high-oleic sunflower oil (Trisun-Extra, SVO). An oleic-acid rich fat blend (MUFA) was obtained by mixing $2.1 \%$ linseed oil, 9.8\% wet-fractionated palm oil-stearin fraction, $10.3 \%$ sunflower oil, plus $77.8 \%$ Trisun- 80 . Triglycerides rich in elaidic acid (Elaidic) were prepared by mixing $33 \%$ free elaidic acid and $67 \%$ of a hydrolyzed fat blend $(9.3 \%$ cocoa butter, $7.5 \%$ fully refined olive oil, $22.2 \%$ palm oil, $28.4 \%$ soy bean oil, plus $32.6 \%$ Trisun-80). Similarly, triglycerides rich in vaccenic acid (Vaccenic) were prepared by mixing $33 \%$ free vaccenic acid and $67 \%$ of the same hydrolyzed fat blend as used for the 'Elaidic' fat. The two trans-fatty acids-containing fat blends were prepared by heating the hydrolyzed fat blend, the free trans-fatty acid, glycerol, and titanium tetra butoxide as a catalyst, with toluene. Esterification was driven towards the formation of triglycerides by gradual removal of water and toluene during temperature programming. Care was taken to prevent trans-esterification reactions (formation of $\beta$-keto esters). Free fatty acids were removed by washing, silica refining, and steaming. 
Table 1

Composition of the five experimental diets

\begin{tabular}{lcrlc}
\hline Diet component & $\mathrm{g} / 1000 \mathrm{~kJ}$ & $\mathrm{~g} / 100 \mathrm{~g}$ & en $(\mathrm{kJ})$ & $\mathrm{en} \%$ \\
\hline Calcium caseinate & 14.64 & 23.565 & 230.1 & 23.0 \\
Fat blend $^{\mathrm{a}}$ & 8.1 & 13.038 & 299.7 & 30.0 \\
Maize starch $_{\text {Solkafloc }}^{34.42}$ & 55.404 & 469.8 & 47.0 \\
Mineral mix RMH89 $^{\mathrm{b}}$ & 3.9 & 6.278 & & \\
Vitamin mix Vit90c $^{\mathrm{c}}$ & 0.86 & 1.384 & & \\
Cholesterol & 0.006 & 0.322 & & \\
Total & 62.126 & 0.010 & & \\
\hline
\end{tabular}

${ }^{a}$ See Section 2.2.

${ }^{\mathrm{b}}$ Composition in $\mathrm{mg} / \mathrm{MJ}$, primary potassium phosphate; $\mathrm{K}_{2} \mathrm{HPO}_{4}$, 112.89; potassium bicarbonate, $\mathrm{KHCO}_{3}, 170.88$; potassium chloride, $\mathrm{KCl}, 83.18$; calcium carbonate, $\mathrm{CaCO}_{3}, 70.11$; secondary magnesium phosphate, $\mathrm{MgHPO}_{4} \cdot 3 \mathrm{H}_{2} \mathrm{O}, 227.21$; tri-sodium citrate-dihydrate, $\mathrm{Na}_{3} \mathrm{C}_{6} \mathrm{H}_{5} \mathrm{O}_{7} \cdot 2 \mathrm{H}_{2} \mathrm{O}, 168.98$; manganese sulfate, $\mathrm{MnSO}_{4} \cdot \mathrm{H}_{2} \mathrm{O}, 12.22$; ferric citrate $(19 \% \mathrm{Fe}), \mathrm{FeC}_{6} \mathrm{H}_{5} \mathrm{O}_{7} \cdot 5 \mathrm{H}_{2} \mathrm{O}, 10.43$; copper citrate $(35 \%$ $\mathrm{Cu}), \mathrm{CuC}_{6} \mathrm{H}_{6} \mathrm{O}_{7} \cdot \times \mathrm{H}_{2} \mathrm{O}, 1.12$; zinc citrate, $\mathrm{Zn}_{3}\left(\mathrm{C}_{6} \mathrm{H}_{5} \mathrm{O}_{7}\right)_{2} \cdot 3 \mathrm{H}_{2} \mathrm{O}$, 2.97; potassium iodate, $\mathrm{KIO}_{3}, 0.017$.

${ }^{\mathrm{c}}$ Composition in $\mathrm{mg} / \mathrm{MJ}$, thiamin mono-nitrate, 0.36 ; riboflavin, 0.36 ; nicotinamide, 1.20; calcium pantothenate, 1.20; choline chloride $50 \%, 119.5$; myo-inositol, 5.98; folic acid, 0.06 ; biotin, 0.012 ; pyridoxine, 0.38; vitamin B12, 3.10; vitamin A (325 IU/mg), 1.84; vitamin D3 (1000 IU/mg), 0.60; vitamin K3 (22.7\%), 0.24; dl- $\alpha$-tocopherol (dry powder $50 \%$ ), 9.56; calcium silicate, 11.95 ; sucrose, 43.658 .

The diets were fed ad libitum, and contained $30 \mathrm{en} \%$ as fat and a background level of $0.01 \%$ cholesterol (Table 1). Cholesterol was added to the diets to induce a modest degree of hyperlipoproteinemia to enhance the effects of the dietary fatty acids on lipoprotein levels [13]. The exchange of the indicated fatty acid was fixed at a level of $10 \mathrm{en} \%$, at the expense of oleic acid. The concentration of fat and the fatty acid composition of the dietary fats in the experimental diets were measured in each test diet, directly following production. Concentration of fat in the experimental diets was determined by extraction with dichloromethane after lyophilization. In the test fats the fatty acid distribution was determined (Table 2) with special emphasis on trans-isomers, using a $50 \mathrm{~m}$ column and an optimized temperature program [14]. In addition, in the experimental diets fatty acid distribution was determined using a standard method [15], immediately following production and after storage of the diets for 4 weeks, to check stability. All diets were prepared once. Portions of each diet for feeding during 2-3 day periods were stored at $-20^{\circ} \mathrm{C}$ under an atmosphere of $\mathrm{N}_{2}$ until use. The diets were fed in powdered form. During the adaptation period all hamsters were fed ad libitum with the MUFA diet.

\subsection{Analyses}

At the end of the experiment, plasma (EDTA as anti-coagulant) lipoproteins VLDL (plus IDL), LDL, and HDL were separated according to the method of

Table 2

Analyzed fatty acid composition of the five dietary fat blends ${ }^{\mathrm{a}}$

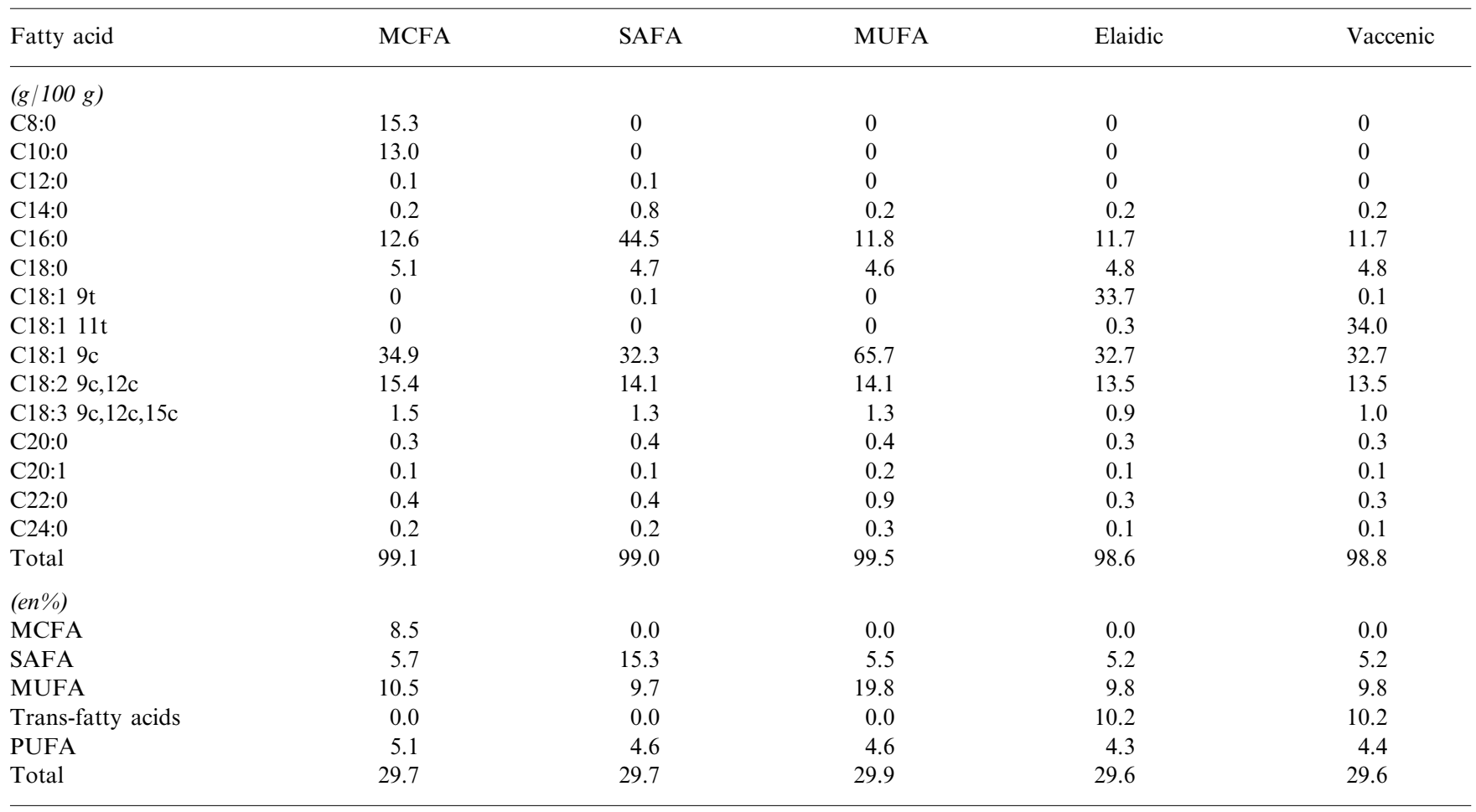

\footnotetext{
${ }^{\text {a }}$ For description of the five fat blends, see Section 2.2.
} 
Pietsch et al. [16]. Plasma was combined for each group in 12 pools of two randomly selected animals each. In the lipoprotein fractions, total and free cholesterol (CHOD-PAP method, Boehringer, Mannheim, Germany), triglycerides (GPO-PAP method, Roche, Basel, Switzerland), phospholipids (Boehringer), and protein [17] (not in HDL because of the albumin present in this fraction) were determined, using commercially available reagent kits on a Cobas Mira S automated analyzer (Roche). The concentration of cholesteryl esters was calculated as the difference between total and free cholesterol concentrations. In all animals $(n=30$ per group) total cholesterol (Boehringer) was measured in whole (EDTA-)plasma before allocation and at the end of the experiment.

CETP activity level was assayed in EDTA-plasma according to Groener et al. [18] with modifications as described earlier [19]. Lecithin:cholesterol acyltransferase (LCAT) activity levels were determined in EDTA-plasma as originally described [20], using the modifications as described [19]. Plasma phospholipid transfer protein (PLTP) activity level was measured as described [21]. CETP, LCAT and PLTP activities were expressed in arbitrary units, i.e. relative to the activity in a human plasma pool ( $\%$ of plasma pool).

Liver total and free cholesterol concentrations were determined as described [22]. From liver homogenate, cholesteryl esters were isolated after extraction according to Folch et al. [23] and separation over a column packed with silica gel. The fatty acid distribution of the liver cholesteryl esters was determined by gas chromatography [15]. Platelets were obtained from platelet-rich plasma, washed in saline, and platelet phospholipids were isolated on a silica column. In three pools of eight animals each per group, the overall and $s n-2$ position distribution of fatty acids in phospholipids were determined by gas chromatography [15]. Fatty acids from the sn-2 position were hydrolyzed by phospholipase-A2 (Sigma P9279) from bee venom.

At dissection, macroscopic examination was performed and liver samples were fixed in formalin, and stained with haematoxylin and eosin for microscopic examination.

\subsection{Statistics}

Data are expressed as mean \pm S.E.M. Statistical analysis was performed using the SAS computer program, version 6.10. One-way analysis of variance (ANOVA) was performed on the parameters measured or, if the data were not distributed normally, the Kruskal-Wallis test was used. The Student-Newman-Keul's multiple comparison test was used to analyze differences between treatment means. The two-sided level of statistical significance was pre-set at $P<0.05$.

\section{Results}

\subsection{Diets}

As intended, detailed analysis of the fatty acid pattern in the dietary fat blends revealed that the MCFA, SAFA, MUFA, Elaidic, and Vaccenic fats were increased with $28-34 \%$ of caprylic (octanoic) and capric (decanoic), palmitic (hexadecanoic), oleic (9c-octadecenoic), elaidic, and vaccenic acid, respectively (Table 2). The fatty acid patterns include fatty acids from mono- and di-acylglycerols and unesterified fatty acids, which were typically present at levels of $<0.1,<5$, and $<0.1 \%$, respectively. The fatty acid composition of the five experimental diets showed a great similarity with the fatty acid profiles of the five experimental fats (data not shown). The dietary fat content varied between 13.1 and $13.7 \mathrm{~g} /$ $100 \mathrm{~g}$ diet (data not shown). Based on the stability of the fatty acid profiles, as analyzed in the diets after storage for four weeks, no deterioration of fatty acids was observed (data not shown).

\subsection{Animal performance}

Clinical observation of the hamsters revealed no abnormalities before and during the study. Body weight was measured weekly and growth was calculated as the change in body weight from the start of the study. Feed intake was measured during four consecutive days in the second and the last week of the experiment. No systematical differences in animal growth and feed intake between the dietary groups were observed (data not shown). This indicates that energy absorption and use must have been similar in all dietary groups. Since the diets differed only in their fatty acid composition, it can also be concluded that fat absorption must have been similar in all the groups.

At the end of the experiment, macroscopic evaluation revealed very slightly pale livers, and a more pronounced lobular pattern, which was more abundant in hamsters fed the MUFA, Elaidic or Vaccenic diets $(P<0.02$; data not shown). This paleness can be attributed to fat deposition in the hepatocytes. Microscopically, a slight vacuolation was observed in hepatocytes from hamsters of all groups. Vacuolation was not accompanied by fibrosis or necrosis, and can therefore be considered as reversible. Inflammatory cell infiltrates, mostly consisting of mononuclear cells, were observed to a similar extent in all the dietary groups. We concluded that there were no distinct pathological effects observed in this study. 
Table 3

Plasma cholesterol, lipid transfer and transferase proteins activity levels and liver cholesterol concentrations in the five experimental groups

\begin{tabular}{|c|c|c|c|c|c|c|}
\hline Measure & MCFA & SAFA & MUFA & Elaidic & Vaccenic & ANOVA \\
\hline \multicolumn{7}{|l|}{ Plasma } \\
\hline Start & $3.91 \pm 0.09^{\mathrm{a}}$ & $3.91 \pm 0.09^{\mathrm{a}}$ & $3.91 \pm 0.09^{\mathrm{a}}$ & $3.90 \pm 0.09^{\mathrm{a}}$ & $3.91 \pm 0.09^{\mathrm{a}}$ & 0.999 \\
\hline End & $3.94 \pm 0.14^{\mathrm{ab}}$ & $4.19 \pm 0.14^{\mathrm{a}}$ & $3.76 \pm 0.13^{\mathrm{ab}}$ & $3.67 \pm 0.11^{\mathrm{b}}$ & $3.95 \pm 0.13^{\mathrm{ab}}$ & 0.053 \\
\hline Free cholesterol $(\mathrm{mM})^{\mathrm{d}}$ & $1.15 \pm 0.04^{\mathrm{ab}}$ & $1.27 \pm 0.04^{\mathrm{a}}$ & $1.11 \pm 0.04^{\mathrm{b}}$ & $1.05 \pm 0.03^{\mathrm{b}}$ & $1.17 \pm 0.04^{\mathrm{ab}}$ & 0.001 \\
\hline Esterified cholesterol $(\mathrm{mM})^{\mathrm{d}}$ & $2.79 \pm 0.11^{\mathrm{a}}$ & $2.93 \pm 0.10^{\mathrm{a}}$ & $2.65 \pm 0.09^{\mathrm{a}}$ & $2.61 \pm 0.08^{\mathrm{a}}$ & $2.78 \pm 0.10^{\mathrm{a}}$ & 0.163 \\
\hline LCAT $(\%)^{\mathrm{c}}$ & $137 \pm 3.4^{\mathrm{ab}}$ & $147 \pm 3.5^{\mathrm{a}}$ & $141 \pm 3.5^{\mathrm{ab}}$ & $132 \pm 2.9^{\mathrm{b}}$ & $147 \pm 4.4^{\mathrm{a}}$ & 0.012 \\
\hline $\operatorname{PLTP}(\%)^{\mathrm{c}}$ & $77 \pm 1.7^{\mathrm{a}}$ & $85 \pm 2.0^{\mathrm{b}}$ & $76 \pm 1.7^{\mathrm{a}}$ & $75 \pm 1.2^{\mathrm{a}}$ & $80 \pm 1.8^{\mathrm{a}}$ & $<0.001$ \\
\hline \multicolumn{7}{|l|}{ Liver } \\
\hline Total cholesterol $(\mu \mathrm{mol} / \mathrm{g})^{\mathrm{d}}$ & $11.5 \pm 0.65^{\mathrm{ab}}$ & $10.0 \pm 0.77^{\mathrm{b}}$ & $12.2 \pm 0.68^{\mathrm{ab}}$ & $13.4 \pm 0.88^{\mathrm{a}}$ & $12.4 \pm 0.55^{\mathrm{ab}}$ & 0.015 \\
\hline Free cholesterol $(\mu \mathrm{mol} / \mathrm{g})^{\mathrm{d}}$ & $7.7 \pm 0.35^{\mathrm{ab}}$ & $6.8 \pm 0.39^{\mathrm{b}}$ & $7.9 \pm 0.40^{\mathrm{ab}}$ & $8.4 \pm 0.53^{\mathrm{a}}$ & $7.9 \pm 0.31^{\mathrm{ab}}$ & 0.087 \\
\hline Esterified cholesterol $(\mu \mathrm{mol} / \mathrm{g})^{\mathrm{d}}$ & $3.8 \pm 0.33^{\mathrm{ab}}$ & $3.2 \pm 0.41^{\mathrm{b}}$ & $4.2 \pm 0.30^{\mathrm{ab}}$ & $5.1 \pm 0.37^{\mathrm{a}}$ & $4.6 \pm 0.28^{\mathrm{a}}$ & 0.002 \\
\hline
\end{tabular}

${ }^{\mathrm{ab}}$ Groups not sharing the same superscript letter differ statistically significantly $(P<0.05$, Student-Newman-Keul's test).

${ }^{c}$ Value for $n=30$ hamsters per group.

${ }^{\mathrm{d}}$ Value for $n=24$ hamsters per group, expressed per g wet weight.Arbitrary unit, i.e. relative to the activity in a human plasma pool (\% of plasma pool).

Table 4

Cholesterol and triglycerides in plasma lipoproteins of the five experimental groups ${ }^{\mathrm{d}}$

\begin{tabular}{|c|c|c|c|c|c|c|}
\hline Measure & MCFA & SAFA & MUFA & Elaidic & Vaccenic & ANOVA \\
\hline \multicolumn{7}{|c|}{ Total cholesterol (mM) } \\
\hline $\mathrm{VLDL}^{\mathrm{e}}$ & $0.71 \pm 0.042^{\mathrm{a}}$ & $0.75 \pm 0.073^{\mathrm{a}}$ & $0.73 \pm 0.050^{\mathrm{a}}$ & $0.60 \pm 0.034^{\mathrm{a}}$ & $0.66 \pm 0.057^{\mathrm{a}}$ & 0.313 \\
\hline HDL & $1.53 \pm 0.051^{\mathrm{a}}$ & $1.56 \pm 0.061^{\mathrm{a}}$ & $1.48 \pm 0.054^{\mathrm{a}}$ & $1.52 \pm 0.053^{\mathrm{a}}$ & $1.52 \pm 0.059^{\mathrm{a}}$ & 0.891 \\
\hline LDL/HDL & $0.67 \pm 0.010^{\mathrm{ab}}$ & $0.70 \pm 0.028^{\mathrm{a}}$ & $0.62 \pm 0.017^{\mathrm{bc}}$ & $0.57 \pm 0.016^{\mathrm{c}}$ & $0.65 \pm 0.018^{\mathrm{ab}}$ & $<0.001$ \\
\hline Recovery ${ }^{\mathrm{f}}$ & $83.1 \pm 0.56^{\mathrm{a}}$ & $82.4 \pm 1.1^{\mathrm{a}}$ & $82.9 \pm 0.61^{\mathrm{a}}$ & $81.2 \pm 0.96^{\mathrm{a}}$ & $81.6 \pm 1.3^{\mathrm{a}}$ & 0.542 \\
\hline $\mathrm{VLDL}^{\mathrm{e}}$ & $1.31 \pm 0.085^{\mathrm{ab}}$ & $1.57 \pm 0.145^{\mathrm{a}}$ & $1.27 \pm 0.120^{\mathrm{ab}}$ & $0.97 \pm 0.063^{\mathrm{b}}$ & $1.23 \pm 0.103^{\mathrm{ab}}$ & 0.007 \\
\hline LDL & $0.082 \pm 0.005^{\mathrm{a}}$ & $0.099 \pm 0.006^{\mathrm{b}}$ & $0.076 \pm 0.004^{\mathrm{a}}$ & $0.070 \pm 0.003^{\mathrm{a}}$ & $0.071 \pm 0.007^{\mathrm{a}}$ & 0.001 \\
\hline HDL & $0.070 \pm 0.005^{\mathrm{a}}$ & $0.073 \pm 0.005^{\mathrm{a}}$ & $0.069 \pm 0.004^{\mathrm{a}}$ & $0.064 \pm 0.004^{\mathrm{a}}$ & $0.067 \pm 0.005^{\mathrm{a}}$ & 0.741 \\
\hline
\end{tabular}

abc Groups not sharing the same superscript letter differ statistically significantly $(P<0.05$, Student-Newman-Keul's test).

d Analyses were performed in 12 pools (of two hamsters each) per group.

${ }^{\mathrm{e}}$ Includes IDL.

${ }^{\mathrm{f}}$ Recovery was calculated as the sum of total cholesterol in (VLDL + LDL + HDL) expressed as percent of total cholesterol in whole plasma.

\subsection{Plasma lipids, lipoproteins and lipid transfer proteins}

Plasma total cholesterol levels tended to be highest in the hamsters fed the SAFA diet and lowest in the hamsters fed the Elaidic diet (Table 3). Only the difference between these two groups was statistically significant. This pattern was reflected in free as well as in esterified cholesterol levels. There were no differences in cholesterol levels between the two groups fed the Vaccenic or the Elaidic diet. Separation of plasma lipoproteins was satisfactory, since calculated recovery for total cholesterol was $>80 \%$ and there were no differences in recovery between the groups. The five dietary groups did not differ significantly in their VLDL-cholesterol concentration, nor in their HDLcholesterol concentration (Table 4). The differences in plasma total cholesterol concentration were mostly reflected in LDL-cholesterol levels. LDL-cholesterol in the hamsters fed the MUFA diet was significantly lower than that in the hamsters fed the SAFA diet. The ratio of LDL:HDL-cholesterol was lower in the hamsters fed the MUFA or Elaidic diets than in those fed the MCFA, SAFA, or Vaccenic diet (Table 4). However, this ratio was statistically significantly lower only in the groups fed the MUFA or Elaidic diet than in the hamsters fed the SAFA diet. VLDL-triglycerides level was highest in hamsters fed the SAFA diet and lowest in their Elaidic diet fed counterparts (Table 4). All groups showed similar levels of CETP activity (Table 3). LCAT activity was highest in the hamsters fed the SAFA or Vaccenic diet and lowest in those fed the Elaidic diet. PLTP activity in the hamsters fed the SAFA diet was significantly higher than in all other 
groups. VLDL of hamsters fed the MUFA or Elaidic diet contained more cholesterol esters and less triglycerides than VLDL of hamsters fed the SAFA diet (Table 5 ), which in turn contained more phospholipids than those of hamsters fed the Elaidic diet. The composition of VLDL from hamsters fed the MCFA or Vaccenic diet was intermediate. As compared with the Vaccenic diet, feeding of the Elaidic diet resulted in VLDL that contained more cholesteryl esters and less triglycerides and phospholipids. A differential effect of the dietary fats on LDL composition was only seen in the phospholipids contents which was higher in LDL from hamsters fed the SAFA diet than in LDL from hamsters fed the MUFA or Elaidic diet. LDL from hamsters fed the Vaccenic diet contained more phospholipids than LDL from hamsters fed the Elaidic diet. The ratio of cholesteryl esters over free cholesterol in HDL was similar in all the dietary groups.

\subsection{Liver lipids}

Contrary to the levels in plasma, total cholesterol concentration in the liver was highest in the hamsters fed the Elaidic diet and lowest in those fed the SAFA diet (Table 3); only this difference was statistically significant. The same pattern was seen for free as well as for esterified cholesterol levels. There were no differences between the two groups fed the two trans-fatty acids diets.

The fatty acid profile of the liver cholesteryl-esters differed largely among the five groups, which was in agreement with the fatty acid composition of the diets (Table 6). Myristic, palmitic (highest in the SAFA group), and stearic acid concentrations were higher in the groups fed the MCFA or SAFA diet. The highest levels of oleic, elaidic, and vaccenic acid were observed in the groups fed the MUFA, Elaidic, and Vaccenic diet, respectively. The level of linoleic acid was lowest in the hamsters fed the MUFA diet. These data demonstrate that the various dietary fatty acids did reach the liver, with the apparent exception for the MCFA as had been anticipated [6]. MCFA are absorbed across the intestinal mucosa and carried directly to the liver in the portal circulation. There they are able to enter the mitochondrial compartment, and are rapidly oxidized to acetyl CoA and can then be used for the de novo synthesis of long-chain fatty acids. Interestingly, conjugated linoleic acid (CLA; C18:2 9c,11t plus C18:2 $9 t, 11 c)$ was found in hepatic cholesteryl esters of hamsters fed the Vaccenic diet.

\subsection{Platelet phospholipids}

Total fatty acid composition, i.e. at the $s n-1$ and the $s n-2$ positions, of platelet phospholipids revealed a higher level of palmitic acid in the hamsters fed the SAFA diet (Table 7). Feeding the Elaidic and Vaccenic diets resulted in a significant incorporation of elaidic acid and vaccenic acid, respectively, in phospholipids. The level of linoleic acid in phospholipids tended to be higher in the hamsters on the SAFA diet and lower in the hamsters fed the MUFA diet. For the $s n-2$ position, the fatty acid distribution did not differ among the five groups. However, there was a small but statistically significant incorporation of elaidic acid at the $s n-2$ position in the hamsters fed the Elaidic diet, whereas

Table 5

Chemical composition of plasma lipoproteins of the five experimental groups ${ }^{\mathrm{d}}$

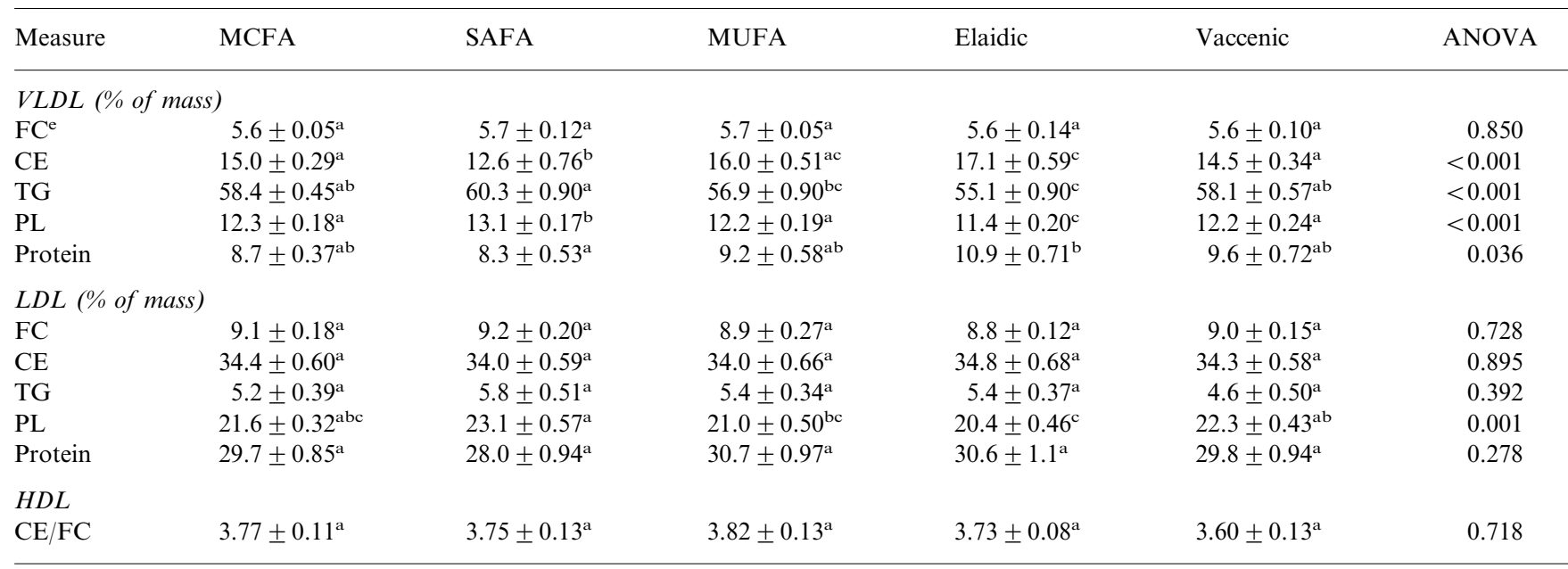

${ }^{a b c}$ Groups not sharing the same superscript letter differ statistically significantly $(P<0.05$, Student-Newman-Keul's test).

${ }^{\mathrm{d}}$ Analyses were performed in 12 pools (of two hamsters each) per group.

${ }^{\mathrm{e}}$ Masses of lipids were calculated using the following molecular weights: free cholesterol $(\mathrm{FC})=387 \mathrm{~g} / \mathrm{mol}$; cholesteryl esters $(\mathrm{CE})=650 \mathrm{~g} / \mathrm{mol}$; triglycerides $(\mathrm{TG})=850 \mathrm{~g} / \mathrm{mol}$; phospholipids $(\mathrm{PL})=775 \mathrm{~g} / \mathrm{mol}$. 
Table 6

Fatty acid composition $(\mathrm{g} / 100 \mathrm{~g})$ of liver cholesteryl esters in the five experimental groups ${ }^{\mathrm{d}}$

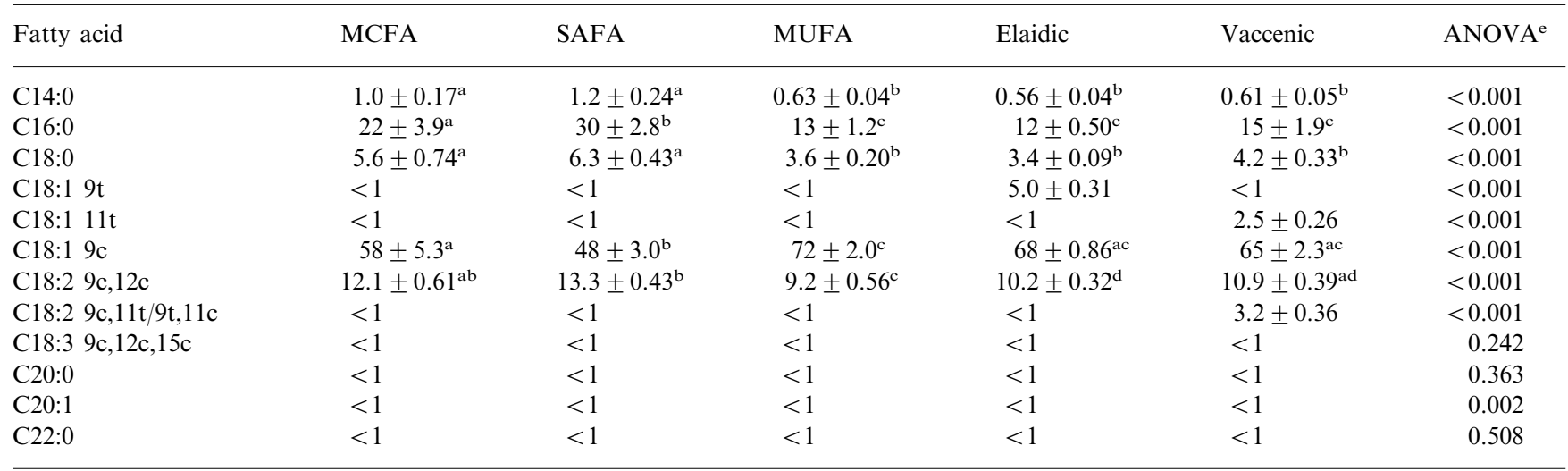

abc Groups not sharing the same superscript letter differ statistically significantly $(P<0.05$, Student-Newman-Keul's test).

${ }^{\mathrm{d}}$ Analyses were performed in eight randomly selected hamsters per dietary group.

${ }^{\mathrm{e}}$ ANOVA after logarithmic transformation of the data.

Table 7

Fatty acid composition $(\mathrm{g} / 100 \mathrm{~g})$ of platelet phospholipids in the five experimental groups ${ }^{\mathrm{d}}$

\begin{tabular}{|c|c|c|c|c|c|c|}
\hline Fatty acid & MCFA & SAFA & MUFA & Elaidic & Vaccenic & ANOVA \\
\hline \multicolumn{7}{|l|}{ Total } \\
\hline $\mathrm{C} 16: 0$ & $21.5 \pm 0.17^{\mathrm{a}}$ & $24.6 \pm 0.24^{\mathrm{b}}$ & $23.2 \pm 0.40^{\mathrm{a}}$ & $22.2 \pm 0.56^{\mathrm{a}}$ & $22.4 \pm 0.60^{\mathrm{a}}$ & 0.005 \\
\hline $\mathrm{C} 18: 0$ & $21.4 \pm 1.7^{\mathrm{a}}$ & $21.3 \pm 2.0^{\mathrm{a}}$ & $26.4 \pm 3.5^{\mathrm{a}}$ & $19.2 \pm 0.79^{\mathrm{a}}$ & $20.0 \pm 0.44^{\mathrm{a}}$ & 0.176 \\
\hline $\mathrm{C} 18: 19 \mathrm{t}$ & $0.0 \pm 0.00^{\mathrm{a}}$ & $0.0 \pm 0.00^{\mathrm{a}}$ & $0.0 \pm 0.00^{\mathrm{a}}$ & $5.8 \pm 0.17^{\mathrm{b}}$ & $0.0 \pm 0.00^{\mathrm{a}}$ & $<0.001$ \\
\hline $\mathrm{C} 18: 111 \mathrm{t}$ & $0.0 \pm 0.00^{\mathrm{a}}$ & $0.0 \pm 0.00^{\mathrm{a}}$ & $0.0 \pm 0.00^{\mathrm{a}}$ & $0.0 \pm 0.00^{\mathrm{a}}$ & $4.2 \pm 0.23^{\mathrm{b}}$ & $<0.001$ \\
\hline $\mathrm{C} 18: 29 \mathrm{c}, 11 \mathrm{t} / 9 \mathrm{t}, 11 \mathrm{c}$ & $0.0 \pm 0.00^{\mathrm{a}}$ & $0.0 \pm 0.00^{\mathrm{a}}$ & $0.0 \pm 0.00^{\mathrm{a}}$ & $0.0 \pm 0.00^{\mathrm{a}}$ & $0.3 \pm 0.00^{\mathrm{b}}$ & $<0.001$ \\
\hline $\mathrm{C} 20: 45 \mathrm{c}, 8 \mathrm{c}, 11 \mathrm{c}, 14 \mathrm{c}$ & $23.0 \pm 1.8^{\mathrm{a}}$ & $24.3 \pm 0.85^{\mathrm{a}}$ & $21.5 \pm 2.5^{\mathrm{a}}$ & $22.8 \pm 0.08^{\mathrm{a}}$ & $23.0 \pm 0.90^{\mathrm{a}}$ & 0.780 \\
\hline $\mathrm{C} 22: 64 \mathrm{c}, 7 \mathrm{c}, 10 \mathrm{c}, 13 \mathrm{c}, 16 \mathrm{c}, 19 \mathrm{c}$ & $2.0 \pm 0.07^{\mathrm{a}}$ & $2.2 \pm 0.13^{\mathrm{a}}$ & $2.4 \pm 0.17^{\mathrm{a}}$ & $2.1 \pm 0.18^{\mathrm{a}}$ & $2.5 \pm 0.22^{\mathrm{a}}$ & 0.291 \\
\hline \multicolumn{7}{|l|}{ sn-2 position } \\
\hline $\mathrm{C} 16: 0$ & $11.1 \pm 2.0^{\mathrm{a}}$ & $8.9 \pm 1.1^{\mathrm{a}}$ & $9.4 \pm 0.48^{\mathrm{a}}$ & $9.6 \pm 0.30^{\mathrm{a}}$ & $10.4 \pm 1.1^{\mathrm{a}}$ & 0.780 \\
\hline $\mathrm{C} 18: 19 \mathrm{c}$ & $18.1 \pm 1.0^{\mathrm{a}}$ & $17.5 \pm 0.58^{\mathrm{a}}$ & $19.2 \pm 0.96^{\mathrm{a}}$ & $18.2 \pm 0.21^{\mathrm{a}}$ & $17.5 \pm 0.47^{\mathrm{a}}$ & 0.575 \\
\hline $\mathrm{C} 18: 29 \mathrm{c}, 12 \mathrm{c}$ & $12.2 \pm 0.36^{\mathrm{a}}$ & $14.3 \pm 1.4^{\mathrm{a}}$ & $10.6 \pm 0.69^{a}$ & $12.8 \pm 0.20^{\mathrm{a}}$ & $13.3 \pm 1.1^{\mathrm{a}}$ & 0.137 \\
\hline $\mathrm{C} 18: 29 \mathrm{c}, 11 \mathrm{t} / 9 \mathrm{t}, 11 \mathrm{c}$ & $0.0 \pm 0.00^{\mathrm{a}}$ & $0.0 \pm 0.00^{\mathrm{a}}$ & $0.0 \pm 0.00^{\mathrm{a}}$ & $0.0 \pm 0.00^{\mathrm{a}}$ & $0.9 \pm 0.09^{\mathrm{b}}$ & 0.010 \\
\hline $\mathrm{C} 20: 45 \mathrm{c}, 8 \mathrm{c}, 11 \mathrm{c}, 14 \mathrm{c}$ & $41.1 \pm 4.4^{\mathrm{a}}$ & $42.9 \pm 2.2^{\mathrm{a}}$ & $44.0 \pm 1.3^{\mathrm{a}}$ & $43.9 \pm 0.49^{\mathrm{a}}$ & $41.5 \pm 1.1^{\mathrm{a}}$ & 0.881 \\
\hline $\mathrm{C} 22: 64 \mathrm{c}, 7 \mathrm{c}, 10 \mathrm{c}, 13 \mathrm{c}, 16 \mathrm{c}, 19 \mathrm{c}$ & $3.2 \pm 0.12^{\mathrm{a}}$ & $4.0 \pm 0.30^{\mathrm{a}}$ & $4.2 \pm 0.25^{\mathrm{a}}$ & $3.8 \pm 0.22^{\mathrm{a}}$ & $4.3 \pm 0.61^{\mathrm{a}}$ & 0.312 \\
\hline
\end{tabular}

${ }^{\text {abc }}$ Groups not sharing the same superscript letter differ statistically significantly $(P<0.05$, Student-Newman-Keul's test).

d Analyses were performed per dietary group in three pools of washed platelets from eight hamsters each.

incorporation of vaccenic acid was negligible in the hamsters on the Vaccenic diet. This difference was not accompanied by differences between these two groups in the level of arachidonic acid (C20:4, $n-6)$ and docosahexaenoic acid (C22:6, $n-3)$. Eicosapentaenoic acid (C20:5 $n-3)$ was not observed in the phospholipids. Thus, levels of eicosanoid precursors in the phospholipids did not differ between the dietary groups. In the phospholipids of the hamsters fed the Vaccenic diet, very low levels of CLA were seen. Incorporation of CLA was mainly at the $s n-2$ position.

\section{Discussion}

The purpose of this study was to investigate the effect of the exchange of a high level (10 en $\%$ ) dietary elaidic acid as opposed to vaccenic acid on parameters of lipid metabolism in vivo. The effects of the two trans-fatty acids were also compared with those of their cis-counterpart oleic acid, medium-chain fatty acids, and palmitic acid in the diet. All diets contained a low background level of cholesterol $(0.01 \%)$ to enhance the effects of the dietary fatty acids on blood (LDL-)cholesterol levels [13]. 
In hamsters, dietary MCFA have been reported not to increase LDL-cholesterol levels, whereas palmitic acid in the diet was found to be hypercholesterolemic [6]. In the current study, dietary fat-induced changes in blood cholesterol levels were mainly reflected in LDL-cholesterol concentrations. The absence of differential effects of the dietary fatty acids on HDL-cholesterol levels in hamsters has been observed by others as well [24]. In this study palmitic acid tended to increase LDL-cholesterol when compared with MCFA, supporting previous findings [6], but this effect was not statistically significant. Oleic acid in the diet has been reported to lower LDL-cholesterol levels when compared with MCFA [24], or myristic acid, which has similar effects as palmitic acid in the hamster [6]. Also in our study oleic acid caused significantly lower LDL-cholesterol levels than palmitic acid, but the difference with the somewhat higher LDLcholesterol levels in the MCFA fed hamsters was not statistically significant. Comparing MCFA, oleic and myristic acid in hamsters, similar observations on blood lipids as in the current study have been reported [25].

When palmitic acid or oleic acid was substituted for MCFA, liver cholesterol concentrations in hamsters have been reported to be lower or higher, respectively $[6,24]$. Also in the current study, compared with the MCFA diet, liver cholesterol concentrations tended to be lower in hamsters on the palmitic acid-rich diet and were very slightly higher after feeding the oleic acid-rich diet.

Plasma CETP activity levels, measured with exogenous substrate as an estimate of CETP mass, were similar after feeding the MCFA, palmitic acid, or oleic-acid rich diets. This observation agrees well with that by Stein et al. [26], who did not find a difference in CETP in hamsters fed a diet with $15 \%$ margarine or $15 \%$ butter. Consequently, the observed differences in the relative levels of cholesteryl esters and triglycerides in VLDL are probably not explained by dietary fatty acids-induced effects on CETP activity. Indeed VLDL cholesteryl ester levels were associated more with liver cholesterol concentrations. Although LCAT activity was higher in hamsters fed the SAFA or Vaccenic diet, and lowest in those fed the Elaidic diet, no differences were observed in the ratio of cholesteryl esters over free cholesterol in HDL, nor in HDL-cholesterol levels. Therefore, the consequence of the observed differences in LCAT activity are not clear. Remarkably, higher plasma PLTP activity in hamsters fed the palmitic acid diet was associated with a higher relative level of phospholipids in VLDL and LDL. Currently the function of PLTP is hypothesized to be modification of HDL subfractions [27] or transfer of phospholipids from apo B containing lipoproteins to HDL [28]. Higher levels of phospholipids in VLDL and LDL are therefore not in line with the higher PLTP activity, and can not be explained at present.
Thus, although in the current study the differences were not always statistically significant, the effects on lipid metabolism in the hamsters by dietary MCFA, palmitic and oleic acid corresponded with the effects observed by others in earlier hamster studies.

In man dietary trans-fatty acids have been reported to simultaneously increase LDL-cholesterol and reduce HDL-cholesterol when compared with oleic acid, or at least raise the ratio LDL/HDL-cholesterol [10]. In hamsters fed ethyl-elaidate, plasma cholesterol was similar, but LDL/HDL-cholesterol was higher and liver cholesterol lower when compared with dietary ethyl-oleate [29]. In another study using hamsters, dietary elaidic acid caused lower liver cholesterol, and higher plasma LDLcholesterol levels when compared with oleic acid in the diet [30]. In the present study, plasma total cholesterol in the two trans-fatty acids fed groups did not differ from that in the hamsters fed the MUFA diet. Also, Nicolosi and co-workers did not observe differences in plasma total cholesterol between hamsters fed trans-fatty acids and those fed oleic acid [25]. LDL-cholesterol levels were slightly, but not statistically significantly, higher in the hamsters fed the Vaccenic diet than in their counterparts fed the Elaidic or the MUFA diet. Thus, the effect of dietary trans-fatty acids on LDL-cholesterol levels in the hamsters varies between studies. In man plasma CETP activity is increased when trans-fatty acids are substituted for oleic acid in the diet [11,12], which may contribute to the increase in LDL-cholesterol and/or reduction in HDL-cholesterol. However, CETP was not affected by the dietary fatty acids in the current hamster experiment. In humans consuming a diet with a very high level of trans-fatty acids ( $8.7 \mathrm{en} \%$ ), serum lipids have been reported to contain increased amounts of CLA that were not derived from the diet [31]. It was hypothesized that CLA had been formed by an effect of $\Delta 9$-desaturase on vaccenic acid from the trans-fatty acids-rich diet. Indeed in the current study in hamsters fed vaccenic acid, but not in those fed elaidic acid, CLA was present in liver cholesteryl esters and platelet phospholipids, providing support for this hypothesis.

The current study is the first to investigate the effects of individual trans-fatty acids isomers on lipid metabolism in vivo. When elaidic and vaccenic acid were compared directly, this study revealed two main differences. The ratio of LDL/HDL-cholesterol in plasma was significantly higher in hamsters fed vaccenic acid than in their elaidic acid fed counterparts. Since this ratio is associated positively with risk for coronary heart disease in humans, the effect of vaccenic acid on blood cholesterol could be considered worse than that of elaidic acid. Elaidic acid was incorporated at low levels, but more efficiently than vaccenic acid at the $s n-2$ position of platelet phospholipids. Eicosanoids are derived from the elongation and desaturation products 
of polyunsaturated fatty acids. Eicosanoids are highly active substances with diverse biological actions, also in processes related to the development of coronary heart disease such as thrombosis and inflammation. Levels of arachidonic acid and docosahexaenoic acid in the phospholipids of both groups fed trans-fatty acids was similar. Eicosapentaenoic acid was not observed in the phospholipids. Thus, levels of eicosanoid precursors in the phospholipids did not differ between the dietary groups. In addition, it seems unlikely that this difference at the observed level of total trans-fatty acids incorporation in phospholipids has consequences for the eicosanoid biosynthesis at an adequate linoleic acid intake [32].

We conclude that the slight differences between elaidic and vaccenic acid in their impact on lipid metabolism do not support discrimination between these two trans-fatty acid isomers in terms of effects relevant for the pathogenesis of coronary heart disease. Thus, this animal study does not provide evidence for the suggestion, based on epidemiological observations $[1,2]$, that elaidic acid would be more detrimental for cardiovascular risk than vaccenic acid.

\section{Acknowledgements}

We thank A Visser for preparation of the triglycerides containing the trans-fatty acids isomers, and $\mathrm{P}$ van den Berg, T van Gent, WJ Kloots and LM Scheek for their expert technical assistance.

\section{References}

[1] Willett WC, Stampfer MJ, Manson JE, et al. Intake of trans fatty acids and risk of coronary heart disease among women. Lancet 1993;341:581-5.

[2] Ascherio A, Hennekens CH, Buring JE, Master C, Stampfer MJ, Willett WC. Trans-fatty acids intake and risk of myocardial infarction. Circulation 1994;89:94-101.

[3] Bolton-Smith C, Woodward M, Fenton S, Brown CA. Does dietary trans fatty-acid intake relate to the prevalence of coronary heart-disease in Scotland. Eur Heart J 1996;17:837-45.

[4] Rosenthal MD, Whitehurst MC. Selective effects of isomeric cis and trans fatty acids on fatty acyl $\Delta 9$ and $\Delta 6$ desaturation by human skin fibroblasts. Biochim Biophys Acta 1983;753:450-9.

[5] Mahfouz MM, Johnson S, Holman RT. The effect of isomeric trans-18:1 acids on the desaturation of palmitic, linoleic and eicosa-8,11,14-trienoic acids by rat liver microsomes. Lipids 1980;15:100-7.

[6] Woollett LA, Spady DK, Dietschy JM. Regulatory effects of the saturated fatty acids 6:0 through 18:0 on hepatic low density lipoprotein receptor activity in the hamster. J Clin Invest 1992;89:1133-41.

[7] Emken EA. Physiochemical properties, intake, and metabolism. In: trans fatty acids and coronary heart disease. Am J Clin Nutr 1995;62:659S-69S.

[8] Terpstra AHM, Laitinen L, Stucchi AF, Nicolosi RJ. The effect of semipurified diets containing two levels (20 and $40 \%$ ) of either casein or soybean protein isolate and concentrate on plasma lipids in hamsters. Nutr Res 1994;14:885-95.

[9] Meijer GW, De Bruijne JJ, Beynen AC. Dietary cholesterol-fat type combinations and carbohydrate and lipid metabolism in rats and mice. Int J Vit Nutr Res 1987;57:319-26.

[10] Katan MB, Zock PL, Mensink RP. Trans fatty acids and their effects on lipoproteins in humans. Ann Rev Nutr 1995;15:47393.

[11] Abbey M, Nestel PJ. Plasma cholesteryl ester transfer protein activity is increased when trans-elaidic acid is substituted for cis-oleic acid in the diet. Atherosclerosis 1994;106:99-107.

[12] Van Tol A, Zock PL, Van Gent T, Scheek LM, Katan MB Dietary trans fatty acids increase serum cholesterylester transfer protein activity in man. Atherosclerosis 1995;115:129-34.

[13] Spady DK, Dietschy JM. Interaction of dietary cholesterol and triglycerides in the regulation of hepatic low density lipoprotein transport in the hamster. J Clin Invest 1988;81:300-9.

[14] AOCS. Official Method Ce 1c-89. Fatty acid composition by Gas Liquid Chromatography, cis, cis and trans isomers, updated 1992.

[15] AOCS. Recommended Practice Ce 1-62. Fatty Acid Composition by Gas Chromatography.

[16] Pietzsch J, Subat S, Nitzsche S, Leonhardt W, Schentke KU, Hanefeld M. Very fast ultracentrifugation of serum lipoproteins: influence on lipoprotein separation and composition. Biochim Biophys Acta 1995;1254:77-88.

[17] Markwell MAK, Haas SM, Biber LL, Tolbert NE. A modification of the Lowry procedure to simplify protein determination in membrane and lipoprotein samples. Anal Biochem 1978;87:20610.

[18] Groener JEM, Pelton RW, Kostner GM. Improved estimation of cholesteryl ester transfer exchange activity in serum or plasma. Clin Chem 1986;32:283-6.

[19] Meijer GW, Demacker PNM, Van Tol A, et al. Plasma activities of lecithin-cholesterol acyltransferase, lipid transfer proteins and post-heparin lipases in inbred strains of rabbits hypo-responsive or hyper-responsive to dietary cholesterol. Biochem J 1993;293:729-34.

[20] Glomset JA, Wright JL. Some properties of a cholesterol esterifying enzyme in human plasma. Biochim Biophys Acta 1964;89:266-76.

[21] Speijer H, Groener JEM, Van Ramshorst E, Van Tol A. Different locations of cholesteryl ester transfer protein and phospholipid transfer protein activities in plasma. Atherosclerosis 1991;90:159-68.

[22] Janssen GB, Meijer GW. Enzymatic determination of lipids in liver extracts. Clin Biochem 1995;28:312-4.

[23] Folch J, Lees M, Sloane-Stanley GH. A simple method for the isolation and purification of total lipids from animal tissues. $\mathrm{J}$ Biol Chem 1957;226:497-509.

[24] Daumerie CM, Woollett LA, Dietschy JM. Fatty acids regulate hepatic low density lipoprotein receptor activity through redistribution of intracellular cholesterol pools. Proc Natl Acad Sci USA 1992;89:10797-801.

[25] Nicolosi RJ, Wilson TA, Rogers EJ, Kritchevsky D. Effects of specific fatty acids $(8: 0,14: 0$, cis-18:1, trans-18:1) on plasma lipoproteins, early atherogenic potential, and LDL oxidative properties in the hamster. J Lipid Res 1998;39:1972-80.

[26] Stein Y, Dabach Y, Hollander G, Stein O. Cholesteryl ester transfer activity in hamster plasma: increase by fat and cholesterol rich diets. Biochim Biophys Acta 1990;1042:138-41.

[27] Jauhiainen M, Metso J, Pahlman R, Blomqvist S, van Tol A, Ehnholm C. Human plasma phospholipid transfer protein causes high density lipoprotein conversion. J Biol Chem 1993;268:4032-6. 
[28] Tall AR, Krumholz S, Olivecrona T, Deckelbaum RJ. Plasma phospholipid transfer protein enhances transfer and exchange of phospholipids between very low density lipoproteins and high density lipoproteins during lipolysis. J Lipid Res 1985;26:84251 .

[29] Ascott MBC, Pollard L, Sanders TAB. Effects of elaidic acid (18:1 n-9 trans) and oleic acid (18:1 n-9 cis) on plasma and hepatic cholesterol concentrations in the hamster. Proc Nutr Soc 1995;54:148A.
[30] Woollett LA, Daumerie CM, Dietschy JM. trans-9-Octadecanoic acid is biologically neutral and does not regulate the low density lipoprotein receptor as the cis isomer does in the hamster. J Lipid Res 1994;35:1661-73.

[31] Salminen I, Mutanen M, Jauhiainen M, Aro A. Dietary trans fatty acids increase conjugated linoleic acid levels in human serum. J Nutr Biochem 1998;9:93-8.

[32] Zevenbergen JL, Haddeman E. Lack of effects of trans fatty acids on eicosanoid biosynthesis with adequate intakes of linoleic acid. Lipids 1989;24:555-63. 